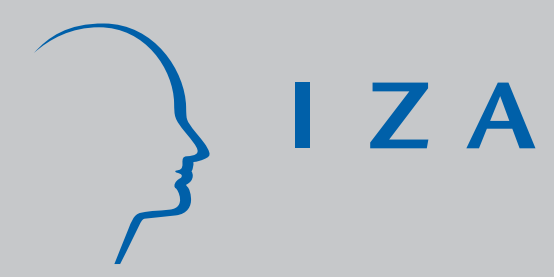

IZA DP No. 1570

Minimum Wage or Negative Income Tax:

Why Skilled Workers May Favor Wage Rigidities

Maya Bacache-Beauvallet

Etienne Lehmann

April 2005 


\title{
Minimum Wage or Negative Income Tax: Why Skilled Workers May Favor Wage Rigidities
}

\author{
Maya Bacache-Beauvallet \\ CEPREMAP, ENS Paris-Jourdan \\ Etienne Lehmann \\ ERMES, University of Paris 2 \\ and IZA Bonn
}

Discussion Paper No. 1570

April 2005

IZA

P.O. Box 7240

53072 Bonn

Germany

Phone: +49-228-3894-0

Fax: +49-228-3894-180

Email: iza@iza.org

\begin{abstract}
Any opinions expressed here are those of the author(s) and not those of the institute. Research disseminated by IZA may include views on policy, but the institute itself takes no institutional policy positions.

The Institute for the Study of Labor (IZA) in Bonn is a local and virtual international research center and a place of communication between science, politics and business. IZA is an independent nonprofit company supported by Deutsche Post World Net. The center is associated with the University of Bonn and offers a stimulating research environment through its research networks, research support, and visitors and doctoral programs. IZA engages in (i) original and internationally competitive research in all fields of labor economics, (ii) development of policy concepts, and (iii) dissemination of research results and concepts to the interested public.
\end{abstract}

IZA Discussion Papers often represent preliminary work and are circulated to encourage discussion. Citation of such a paper should account for its provisional character. A revised version may be available directly from the author. 
IZA Discussion Paper No. 1570

April 2005

\section{ABSTRACT \\ Minimum Wage or Negative Income Tax: Why Skilled Workers May Favor Wage Rigidities*}

This article studies the political choice over the extent and the means of income redistribution between high and low skilled workers. Redistributive tools encompass fiscal transfers with negative income tax and minimum wage. Using fiscal instruments only is assumed optimal. We show that high skilled workers may favor a second-best minimum wage requirement. This is because minimum wage increases unemployment, hence the marginal cost of redistribution is higher which gives a pretext for high skilled workers to moderate low skilled workers claim for income redistribution.

JEL Classification: D78, E24, H23, J38

Keywords: unemployment, political economics, income redistribution, minimum wage

Corresponding author:

Etienne Lehmann

University of Paris II Panthéon-Assas

ERMES (FRE 2887 CNRS)

12 place du Panthéon

75230 Paris Cedex 05

France

Email: elehmann@u-paris2.fr

\footnotetext{
* We wish to thank for remarks on earlier versions participants in seminars at Louvain La Neuve, ERMES Paris 2, EUREQua Paris 1, and in particular, Pierre Cahuc and Bernard Salanié.
} 


\section{Introduction}

We argue that it may be in high skilled workers' interest to redistribute income from high to low skilled workers through wage rigidities rather than through fiscal tools. We develop this argument in a political economic model where the choice is not only on the extent but also on the means of redistribution. Income can be transferred though the tax-benefit system and through a wage rigidity mechanism that comes from a minimum wage requirement and unemployment benefits. In our simplified framework, labor supply is exogenous and redistributing income through fiscal means only is optimal because it maximizes the total amount of resources. However, we show that it may be in high skilled workers' interest to restrict the set of instruments. Put differently, a second-best redistributive system that generates unemployment may be in high skilled workers' interest. This is because when redistribution occurs through minimum wage and unemployment benefits, its marginal cost is higher, which gives to high skilled workers a pretext to moderate low skilled workers' claim for redistribution.

Comparing the cases of France and UK illustrates the contrast between a wage rigidity and a fiscal redistributive strategy. We use average effective tax rates by decile group of gross earnings (including employer social contribution) computed thanks to EUROMOD datasets (see Table 2a of Immervoll 2004). The bottom-top ratio of one minus this indicator is a measure of how redistributive is income taxation in a given country. We compute this ratio and obtain 1.32 for France and 1.48 for UK. At the same time, unemployment rates are respectively $11.5 \%$ and $6.1 \%$. Hence, France seems to use fiscal instruments less than UK and this seems to generate a higher level of unemployment. Our purpose in this paper is not discuss the normative trade-off between wage rigidity and fiscal redistribution. Rather, it is to show that the political process leads to an inefficient "policy-mix" with two much wage rigidities and too few fiscal redistribution. Piketty (1999) documents how difficult it was to implement a fiscal reform in France. In the nineties, French governments faced ideological oppositions to tax-cut programs in employers' social contributions on low paid jobs. Theses programs intended to reduce 
the costs of minimum wage in terms of unemployment. In our framework, this can be interpreted as a partial substitution of fiscal means to wage rigidity mechanisms. Our model suggests an explanation to these ideological reluctances documented by Piketty (1999). We argue these reluctances were driven by high skilled workers' interests to reduce the amount of redistribution.

An important assumption in our model is the following. The set of available redistributive tools can be restricted during an institutional stage where it will turn that high skilled workers have a veto power. Then, the political stage determines the levels of redistributive tools through a standard political process. Our distinction between these two stages is consistent with Buchanan and Tullock (1962)' idea that constitutional and political decisions are distinct. We consider only two institutional settings depending on whether or not negative income tax is available. The case of France justifies this assumption, since in January 2001, the conseil constitutionnel (constitutional court) has indeed censured a program of negative income tax. We assume that unanimity is required at the institutional stage to modify a historically predetermined rule. To modify the institutional rule is costly enough not to engage in a political fight and to require (almost) unanimous agreement. Indeed, we may consider that the main institutional switch that happened in past decades occurred during the 1983 Wasenaar general agreements between the dutch government, labor and employer unions (see Nickell and van Ours 2000) ${ }^{1}$. Hence, switching fiscal rule is possible but difficult.

Our paper contributes to the political economic literature such as Epstein and Nizan (1999) and Saint-Paul (1994, 1996a, 1996b, 2000). One motivation for this approach is the empirical finding of Sobel (1999). He studies the empirical determinants of minimum wage in the United States and gives evidence that minimum wage is not set according to normative causes but is the outcome of a political process. In particular, Saint Paul (2000) political insiders theory argues that low skilled employed workers benefit from higher minimum wage whereas low skilled unemployment workers

\footnotetext{
${ }^{1}$ One key element of these agreements was a wage moderation that happened not to increase income inequalities. This is the reason why we consider the Wasenaar agreements as a switch in the institutional rule, although it encompasses many other aspects.
} 
bear the costs in terms of unemployment. In contrast, we argue that wage rigidity is supported by high skilled workers. We differ from Saint Paul (2000) in two aspects. First, Saint Paul does not consider the existence of fiscal tools as an alternative to minimum wage. However, he considers that employed and unemployed workers are not politically equivalent whereas we do. Hence, we think that our theories are not substitute but complement.

The paper is organized as follows. Section II presents the basic model. The political equilibrium is solved in section III when negative income tax is allowed and in section IV when negative income tax is forbidden. Section V compares the two outcomes. Concluding remarks are given in section VI.

\section{The basic assumptions}

A representative firm produces goods with low $(\ell)$ and high $(h)$ skilled labor as sole inputs. For $i=h, \ell$, we denote by $L_{i}, W_{i}, w_{i}, \tau_{i}$ the (endogenous) levels of employment, pre-tax wages, after-tax wages and tax rates, with $w_{i}=\left(1-\tau_{i}\right) W_{i}$. The number of unemployed workers is $u$. The (exogenous) level of labor supply is $N_{i}$. We normalize the size of the low skilled labor force $N_{\ell}=1$. Since labor supply is exogenous, preferences depend only on after-tax income through the utility function ${ }^{2} \log ($.$) .$ Goods and high skilled labor markets are perfectly competitive. Low skilled labor market may not be competitive because the government is able to enforce a minimum wage requirement $W_{\ell} \geq \bar{W}_{\ell}$. If this minimum wage constraint is not binding, $W_{\ell}$ is determined competitively. Hence, unemployment can only occur in the low-skilled labor market and only when minimum wage is binding. One gets:

$$
u=1-L_{\ell} \quad L_{h}=N_{h}
$$

Low skilled unemployed workers receive unemployment benefits which (endogenous) level is $b$. The government's budget constraint writes:

$$
u \cdot b=\tau_{\ell} \cdot W_{\ell}(1-u)+\tau_{h} \cdot W_{h} \cdot N_{h}
$$

\footnotetext{
${ }^{2}$ While the functional form is unimportant, the risk aversion assumption matters.
} 
The timing of the model is described by three successive stages: an institutional, a political and an economic one.

The institutional stage At the beginning of the model, for exogenous historical reasons, negative income tax is either allowed or forbidden (i.e. whether or not $\tau_{i} \leq 0$ is feasible). This rule (called thereafter fiscal rule) constraints the set of fiscal instruments available during the political stage. Changing such a rule is a huge institutional process. Hence, we assume that a consensus is required to change the fiscal rule during the institutional stage.

The political stage The government chooses the levels of taxes $\tau_{\ell}$ and $\tau_{h}$, unemployment benefits $b$ and the minimum wage requirement $\bar{W}_{\ell}$. There are different possible micro-foundations for the policymaking process such as voting, political competition, lobbying ... (see Persson and Tabellini 2002). We use a reduced form of the political process by assuming that the government maximizes a political function $P($.$) . This function is an aggregate of workers' utility. Political decisions are$ taken before low skilled workers learn whether they are employed or not. We assume that the unemployment risk is equally shared among low skilled workers. Hence, they influence the government's objective only through their expected utility. Therefore, the political objective function has only two arguments, namely, high skilled workers' utility and low skilled workers' expected utility. Without loss of generality, we assume a linear weighted political objective of the form:

$$
P=(1-u) \log w_{\ell}+u \cdot \log b+\gamma \cdot N_{h} \cdot \log \left(w_{h}\right)
$$

where $\gamma$ is an exogenous parameter that stands for the political strength of high skilled workers. The lower $\gamma$, the higher the political pressure for income redistribution. The range of the political strength will be constrained so that redistribution can only occur from high to low skilled workers, but still leaves high skilled workers better of (see equation (16) below).

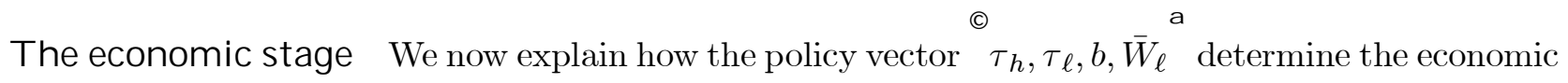
outcome $\left\{w_{\ell}, w_{h}, u\right\}$. The production function is increasing and concave in both arguments and 
exhibits constant returns to scales. For ease of presentation, we assume a Cobb-Douglas technology:

$$
Y=\left(L_{\ell}\right)^{\alpha}\left(L_{h}\right)^{1-\alpha}
$$

where $Y$ denotes output and $\alpha \in(0,1)$. Given (1), the inversed labor demand functions are:

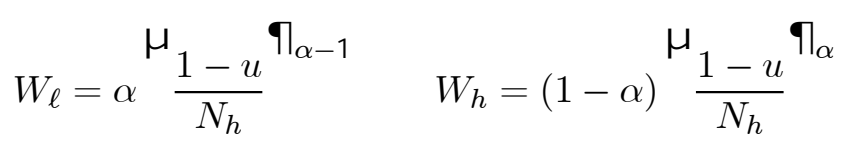

Hence, choosing the minimum wage requirement $\bar{W}_{\ell}$ is equivalent to choose the unemployment rate $u$. Then, we can express after-tax wages and output as functions only of unemployment rate $u$, and tax rates $\tau_{\ell}$ and $\tau_{h}$ :

$$
\begin{aligned}
w_{\ell} & =\alpha\left(1-\tau_{\ell}\right){\frac{1-u}{N_{h}}}^{\mathfrak{q}_{\alpha-1}} \\
w_{h} & =(1-\alpha)\left(1-\tau_{h}\right) \frac{1-u}{N_{h}} \\
Y & =(1-u)^{\alpha}\left(N_{h}\right)^{1-\alpha}
\end{aligned}
$$

The zero profit condition $(1-u) W_{\ell}+N_{h} \cdot W_{h}=Y$ and the budget constraint (2) give:

$$
(1-u) w_{\ell}+u \cdot b+N_{h} \cdot w_{h}=Y
$$

On the supply-side of the labor market, we have to insure that skilled workers do not mimic unskilled workers' behavior, and that the skilled worker participate to the labor market. We impose the following constraints:

$$
\begin{aligned}
& \log w_{h} \geq(1-u) \log w_{\ell}+u \cdot \log b \\
& \log w_{\ell} \geq \log b
\end{aligned}
$$

High skilled workers' participation constraint has to hold at the laissez faire. Let $x^{0}$ be the value taken by any variable in the laissez faire economy. Then, from (5) and (6), incomes are given by

$$
w_{\ell}^{0}=\alpha\left(N_{h}\right)^{1-\alpha} \quad w_{h}^{0}=(1-\alpha)\left(N_{h}\right)^{-\alpha}
$$

Equation (9) holds only if:

$$
\frac{1-\alpha}{\alpha}>N_{h}
$$

which we henceforth assume. The model is solved by backward induction. 


\section{Negative Income Tax is allowed}

In this section, we assume that negative income tax is allowed at the institutional stage. We then solve the political stage. The government chooses tax rates $\tau_{\ell}$ and $\tau_{h}$, unemployed benefits $b$ and the minimum wage requirement $\bar{W}_{\ell}$ to maximize its political objective (3) subject to the budget constraint (2) and the labor market equations (5), (6), (9) and (10).

As it is proved in appendix A.1, when the sign of the tax rates is not constrained, the government chooses not to use a minimum wage requirement and full employment holds $u=0$. The reason is straightforward. The government has two ways of increasing low skilled workers' income: fiscal transfers $\tau_{\ell}<\tau_{h}$ or wage rigidities through unemployment benefits $b$ and the minimum wage requirement $\bar{W}_{\ell}$. In our model, fiscal tools are not distortive and do not reduce total output $Y$ since labor supply is exogenous. In contrast, using a minimum wage requirement reduces the low skilled employment level and total output $Y$. Hence, it is optimal to have a competitive labor market with $u=0$ and to transfer income by fiscal means only. Since there is no unemployment, the choice of unemployment benefit $b$ is irrelevant. Eventually, the level of output equals its laissez faire value, which is according to $(7)$ :

$$
Y^{0}=\left(N_{h}\right)^{1-\alpha}
$$

The political choice determines how this maximized output $Y=Y^{0}$ is shared between high and low skilled workers. Choosing tax rates $\tau_{\ell}$ and $\tau_{h}$ ends up in choosing after-tax income $w_{\ell}$ and $w_{h}$. From equation (8), since $u=0$, the economic trade-off between high and low skilled workers' income is described by function $\phi($.$) according to:$

$$
w_{h}=\phi\left(w_{\ell}\right) \equiv \frac{Y^{0}-w_{\ell}}{N_{h}}
$$

We define the marginal cost of redistribution from high skilled workers' viewpoint:

$$
\phi^{\prime}\left(w_{\ell}\right)=-\frac{1}{N_{h}}
$$

This equation means that to increase low skilled workers' income by one Euro, high skilled workers' 
income must decrease by $1 / N_{h}$ Euro. Therefore, the maximization program of the government is reduced to:

$$
\max _{w_{\ell}, w_{h}} \log w_{\ell}+\gamma \cdot N_{h} \cdot \log w_{h} \quad \text { s.t }: w_{h}=\phi\left(w_{\ell}\right)
$$

The solution is:

$$
w_{\ell}=\frac{1}{1+\gamma \cdot N_{h}} Y^{0} \quad \text { and } \quad w_{h}=\frac{\gamma}{1+\gamma \cdot N_{h}} Y^{0}
$$

The politically stronger high skilled workers are (that is the higher $\gamma$ ) the higher is their net income. In particular, one needs to assume $\gamma>1$ to insure that $w_{h}>w_{\ell}$ so that the participation constraint (9) is verified. Further, from equation (2), one gets

$$
\tau_{\ell} \cdot W_{\ell}+\tau_{h} \cdot N_{h} \cdot W_{h}=0
$$

and the two tax rates are of opposite signs $\tau_{\ell} \cdot \tau_{h}<0$. Therefore, the political equilibrium requires negative income taxes to be allowed at the institutional stage. Finally, redistribution is in favor of low skilled workers (i.e. $\left.\tau_{\ell}<0<\tau_{h}\right)$ if and only if $w_{\ell}>W_{\ell}=w_{\ell}^{0}$ which leads to $\gamma<(1-\alpha) /\left(\alpha \cdot N_{h}\right)$. In the rest of the paper, we assume the high skilled workers' political strength verifies:

$$
1<\gamma<\frac{1-\alpha}{\alpha \cdot N_{h}}
$$

\section{N egative Income Tax is forbidden}

In this section, we assume that at the institutional stage, negative income tax is forbidden. The government chooses tax rates $\tau_{\ell}$ and $\tau_{h}$, unemployed benefits $b$ and the minimum wage requirement $\bar{W}_{\ell}$ to maximize its political objective (3) subject to the budget constraint (2), the institutional constraints $\tau_{i} \geq 0$ for $i=h, \ell$ and the labor market equations (5), (6), (9) and (10).

In the previous section, we have shown that when the fiscal rule allows for negative income tax, the government chooses $\tau_{\ell}<0$. Hence, when the fiscal rule forbids negative income tax, the constraint $\tau_{\ell} \geq 0$ is binding and $\tau_{\ell}=0$. Low skilled workers pre-tax and after-tax wages are equal $w_{\ell}=W_{\ell}$. So, the only way to increase low skilled workers' income is through a minimum wage 
$\bar{W}_{\ell}=w_{\ell}$. In our model, redistributing more income to low skilled employed workers necessarily increases unemployment and decreases output. From (5), unemployment is given by:

$$
1-u=N_{h}{ }^{\mu}{\frac{\alpha}{w_{\ell}}}^{\text {ๆ } \frac{1}{1-\alpha}}
$$

and output depends on $w_{\ell}$ through $Y=\bar{Y}\left(w_{\ell}\right)$ where:

$$
\bar{Y}\left(w_{\ell}\right)=N_{h}{\frac{\alpha}{w_{\ell}}}^{\text {ी } \frac{\alpha}{1-\alpha}} \quad \text { providing } \quad w_{\ell}=\bar{W}_{\ell} \geq w_{\ell}^{0}
$$

In our model, there is no moral hazard since there is no endogenous job search effort. Moreover, the set of policy instruments is large enough to allow for perfect unemployment insurance. Hence, as we formally prove in Appendix A.2, the unemployment risk is perfectly insured:

$$
b=w_{\ell}=\bar{W}_{\ell}
$$

In sum, the government has only one degree of freedom left. Setting the minimum wage requirement $\bar{W}_{\ell}$ results in choosing the low skilled after-tax wage $w_{\ell}$ and the unemployment benefit $b$. From equations (17) and (18), it sets the level of unemployment $u$ and of output $Y$. Finally, we get high skilled workers' income $w_{h}$ and tax rate $\tau_{h}$ through equations (8) and (2). Therefore, the economic trade-off between high and low skilled workers' income is described in this case by function $\bar{\phi}($. according to:

$$
w_{h}=\bar{\phi}\left(w_{\ell}\right) \equiv \frac{\bar{Y}\left(w_{\ell}\right)-w_{\ell}}{N_{h}}
$$

Redistributing income and forbidding negative income tax reduces output. Hence, a given low skilled workers' income above the laissez faire costs more from skilled workers' viewpoint $\bar{\phi}\left(w_{\ell}\right)<\phi\left(w_{\ell}\right)$ whenever redistribution occurs, that is $w_{\ell}>w_{\ell}^{0}$. The marginal cost of redistribution now equals:

$$
\bar{\phi}^{\prime}\left(w_{\ell}\right)=\frac{\bar{Y}^{\prime}\left(w_{\ell}\right)-1}{N_{h}}<\phi^{\prime}\left(w_{\ell}\right)
$$

A rise in low skilled workers' income has now two effects on high skilled workers' income. First, as in the previous section, for a given level of output, a unit increase in low skilled workers' income requires a decrease of high skilled workers' income of $1 / N_{h}$, according to (8). Second, the rise in 
minimum wage increases unemployment and decreases total output. This effect is captured by the term $\bar{Y}^{\prime}\left(w_{\ell}\right)$. Not only the cost of redistribution, but also its marginal cost is eventually higher when negative income tax is forbidden. Furthermore, only equilibria with $w_{\ell} \geq w_{\ell}^{0}$ are now feasible.

The maximization program of the government reduces to:

$$
\max _{w_{\ell}, w_{h}} \log w_{\ell}+\gamma \cdot N_{h} \cdot \log w_{h} \quad \text { s.t }: w_{h}=\bar{\phi}\left(w_{\ell}\right)
$$

The resolution of this program is detailed in Appendix A.2. A corner solution with $w_{i}=w_{i}^{0}$ occurs if:

$$
\gamma \geq \frac{1}{N_{h}} \cdot \frac{(1-\alpha)^{2}}{1-(1-\alpha)^{2}}
$$

This condition is more restrictive than (16) because the marginal cost of redistribution is higher. When this condition is satisfied, one obtains an interior solution with:

$$
\frac{w_{h}}{w_{\ell}}=\gamma \quad 1+\frac{N}{h}^{\mu \alpha}{\frac{\alpha}{w_{\ell}}}^{\text {П } \frac{1}{1-\alpha} !}>\gamma
$$

Because the marginal cost of redistribution is higher than in the previous section, redistribution is weaker and $w_{h} / w_{\ell}$ is higher.

\section{Comparison}

In this section, we turn to the institutional stage. The choice is whether negative income is allowed or not. As we have assumed, a consensus is required to modify the fiscal rule. Hence, if one rule Paretodominates the other, it is adopted. Otherwise, the historically given fiscal rule is kept. Reasoning by backward induction, we thus compare the political equilibria under the two alternatives.

As it was shown, the two political equilibria reduce to maximizing the same objective $\log w_{\ell}+$ $\gamma \cdot N_{h} \cdot \log w_{h}$ with respect to $w_{h}$ and $w_{\ell}$, but under two different constraints (see 14 and 21). If negative income tax is allowed, the constraint is $w_{h}=\phi\left(w_{\ell}\right)$ (given in equation 12). Otherwise, it is $w_{h}=\bar{\phi}\left(w_{\ell}\right)$ (see equation 19). Therefore, the two political equilibria can be easily compared graphically in a $\left(w_{\ell}, w_{h}\right)$ plane. The two constraints are depicted by downwards slopping curves that 
intersects at the laissez faire outcome $\left(w_{\ell}^{0}, w_{h}^{0}\right)$. They are labelled $\phi$ and $\bar{\phi}$ in Figures 1,2 and 3 . When negative tax is forbidden, redistribution occurs through a rise in minimum wage requirement that decreases total output. Hence, the $\bar{\phi}$ curve is steeper than the $\phi$ curve. The political indifference curves are labeled $P P$. The political outcome when negative income tax is allowed (respectively forbidden) is depicted by point $Q$ (resp. $P$ ).

There are only 3 possible cases.

1. According to equations (16) and (22), if

$$
\frac{1}{N_{h}} \cdot \frac{(1-\alpha)^{2}}{1-(1-\alpha)^{2}} \leq \gamma<\frac{1}{N_{h}} \cdot \frac{1-\alpha}{\alpha}
$$

redistribution occurs only when negative income tax is allowed. Consequently, high skilled workers are better of when negative tax is forbidden for no redistribution occurs. The difference in the marginal cost of redistribution gives a pretext for high skilled workers to oppose income redistribution. Conversely, low skilled workers' income is lower. Therefore, at the institutional stage, the fiscal rule remains unchanged because unanimity lacks. This case in depicted in Figure 1.

2. If

$$
\gamma<\frac{1}{N_{h}} \cdot \frac{(1-\alpha)^{2}}{1-(1-\alpha)^{2}}
$$

redistribution occurs under both fiscal rules. Two mechanisms explain the differences in outcomes between the two cases. First, output is lower when negative income tax is forbidden because redistribution occurs through minimum wage that gives rise to unemployment (Income effect). According to this effect, forbidding negative income tax decreases both high and low skilled workers' after-tax income. Second, when negative income tax is forbidden, the extent of redistribution is reduced because the marginal cost of redistribution is higher (Substitution effect). According to this effect, forbidding negative income tax increases (decreases) high (low) skilled workers' after-tax income. Hence, while low skilled are always better off when negative 


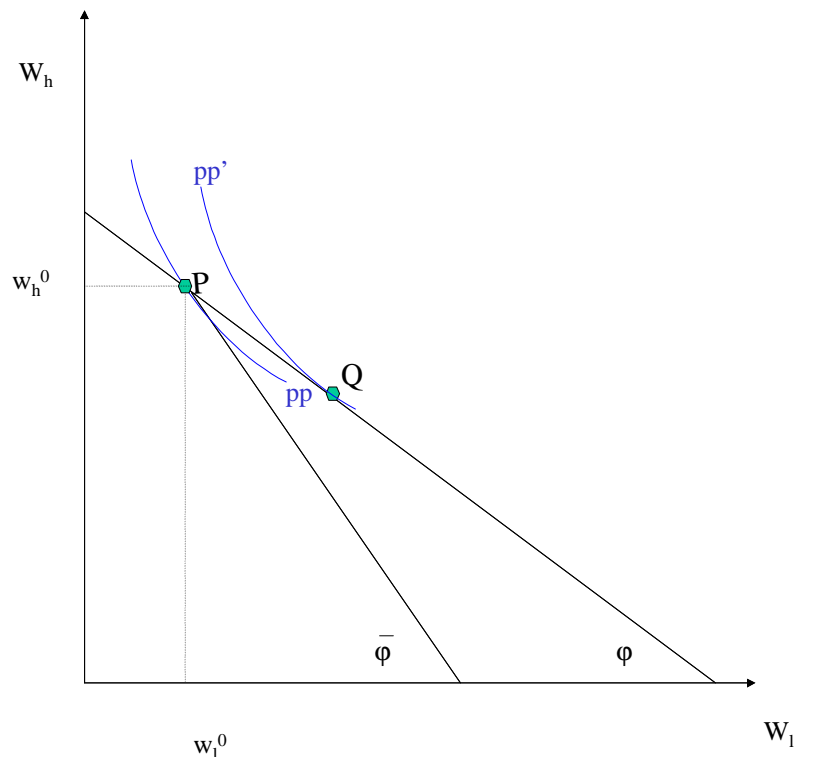

Figure 1: Case 1

income tax is allowed, the comparison for high skilled workers depends on whether or not the income effect dominates the substitution one. Hence, we distinguish two subcases.

(a) If

$$
\frac{1-\alpha \underset{h}{h} \frac{\mathrm{h}}{N_{h} \cdot \alpha 1+(1-\alpha)^{\frac{\alpha-1}{\alpha}}} \mathrm{i}}{\mathrm{h}}<\gamma<\frac{1}{N_{h}} \cdot \frac{(1-\alpha)^{2}}{1-(1-\alpha)^{\frac{\alpha-1}{\alpha}}}
$$

the substitution effect dominates the income one. It implies that redistribution when negative income tax is forbidden is very low. This configuration is depicted in Figure 2. High skilled workers oppose negative income tax while low skilled workers favor it. Therefore, at the institutional stage, the fiscal rule remains unchanged. In particular, if for historical reason, negative income is forbidden, it remains forbidden. Redistribution induces unemployment in a Pareto-inefficient way. As depicted in Figure 2, the reached outcome is $P$. Clearly, allowing at the institutional stage for negative income tax and reaching an outcome on segment $[R, S]$ at the political stage is Pareto-dominant. But such a switch requires that low skilled workers pre-commit during the institutional stage not to ask for outcome $Q$ during the political stage. Such a pre-commitment is not credible. 
Unemployment is therefore the inefficient political way for high skilled workers to moderate low skilled workers' claim for redistribution.

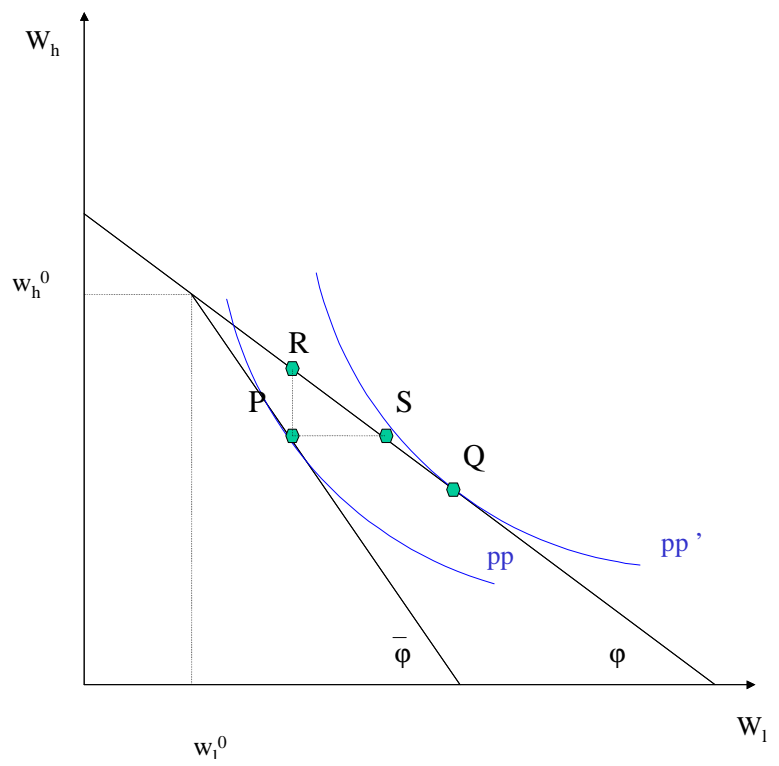

Figure 2: Case 2.a

(b) If

$$
\gamma \leq \frac{1-\alpha \frac{\mathrm{h}}{\mathrm{h}}+(1-\alpha)^{\frac{\alpha-1}{\alpha}} \mathrm{i}}{N_{h} \cdot \alpha 1+(1-\alpha)^{\frac{\alpha-1}{\alpha}}}
$$

The income effect dominates. Both high and low skilled workers are better off when negative tax is allowed. Hence, at the institutional stage, unanimity arises for allowing negative income tax.

When high skilled workers' political strength $\gamma$ is high, the first configuration occurs and there is no redistribution (see equation 23). In particular, high skilled workers' income is higher when negative income tax is forbidden. When $\gamma$ decreases in the neighborhood of $\frac{1}{N_{h}} \cdot \frac{(1-\alpha)^{2}}{1-(1-\alpha)^{2}}$, by continuity, high skilled workers' income remains higher when negative income tax is forbidden. Consequently, case 2a occurs when $\gamma$ is lower "but not too much" than $\frac{1}{N_{h}} \cdot \frac{(1-\alpha)^{2}}{1-(1-\alpha)^{2}}$. Hence, case $2 \mathrm{~b}$ might only emerge for "very" low values of $\gamma$. 


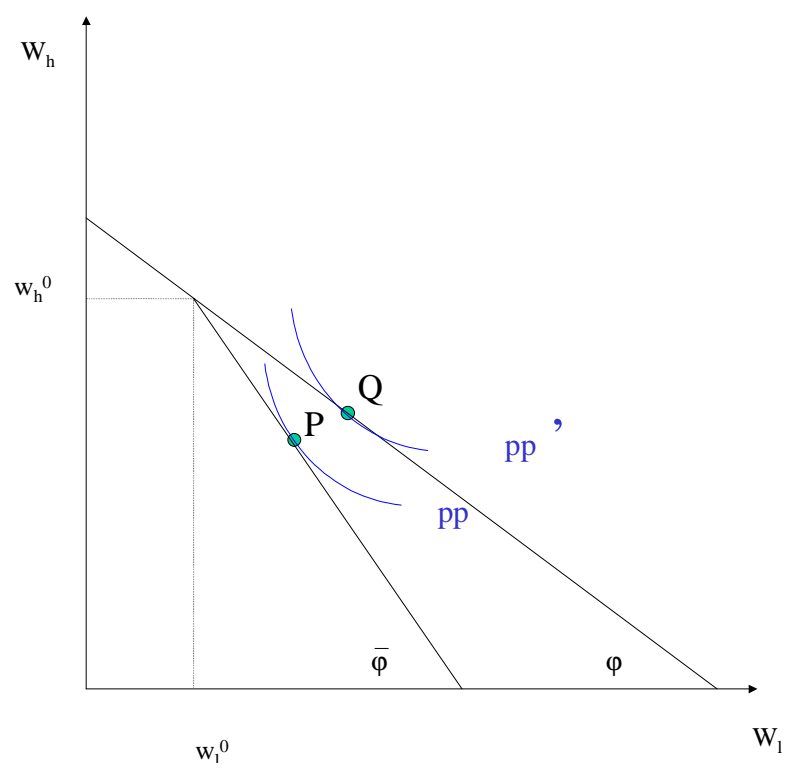

Figure 3: Case 2b

\section{Concluding remarks}

In this paper, we show that forbidding negative income tax reduces the extent of income redistribution from high to low skilled workers. This is the reason why high skilled workers may prefer such second-best redistribution scheme, although it generates unemployment. We show that in our model, only two configurations with redistribution are possible: one where redistribution occurs inefficiently through minimum wage with unemployment; one with higher level of redistribution and no unemployment. Hence we show that high skilled workers may have reasons to oppose structural reforms on redistributive policies.

We now discuss how robust we think our results are. First, we have assumed very specific functional forms: a log utility function, a Cobb-Douglas technology and a linear political objective. These simplifying assumptions were made only for expositional purposes Under more general specifications, the economic mechanisms that we have highlighted remain provided: 1) workers utility function is concave 2) The production function exhibits constant returns to scale and is increasing and concave in both arguments 3 ) the political objective is increasing and weakly concave in its both arguments, 
namely high and low skilled workers' expected utility 4) programs (14) and (21) remain concave ${ }^{3}$.

Second, we have assumed exogenous labor supply and perfect competition (except for the minimum wage requirement in the low skilled labor market). Therefore, by assumption, minimum wage has no role to play when negative income tax is allowed. Our assumptions are clearly too strong. However, when labor supply is endogenous, Allen (1987) shows that a non-linear income taxation without minimum wage remains optimal. Furthermore, one may wonder what would happen in a more realistic environment with more market imperfections so that a minimum wage would have a normative role to play. We conjecture that in such environments, our argument holds in the following form: high skilled workers may support an inefficiently high level of minimum wage that lessens redistribution but also employment.

\section{A Appendix}

During the political stage, the government considers the responses of the labor market to the policy chosen. These responses are given by the labor demand equations (5) (6) and by the budget constraint. We can derive the level of unemployment benefits $b$ thanks to the budget constraint (2) and to equation (4):

$$
u \cdot b=\left[\alpha \cdot \tau_{\ell}+(1-\alpha) \tau_{h}\right](1-u)^{\alpha}\left(N_{h}\right)^{1-\alpha}
$$

Hence, for the government, choosing tax rates $\tau_{h}, \tau_{\ell}$, unemployment benefits $b$ and minimum wage requirement $\bar{W}_{\ell}$ given their labor market effects is equivalent to maximize the political objective reexpressed as a function of only $u, \tau_{\ell}$ and $\tau_{h}$ :

$$
(1-u) \log w_{\ell}+u \cdot \log b+\gamma \cdot N_{h} \cdot \log \left(w_{h}\right)=\Omega\left(u, \tau_{\ell}, \tau_{h}\right)
$$

\footnotetext{
${ }^{3}$ This is formally proved in an Appendix available on request.
} 
where we define for $u>0$ function $\Omega(., .,$.$) according to:$

$$
\begin{aligned}
& \Omega\left(u, \tau_{\ell}, \tau_{h}\right) \equiv(1-u) \log \alpha\left(1-\tau_{\ell}\right){ }^{\mu} \frac{1-u^{\mathfrak{ी}_{\alpha-1}}}{N_{h}}+u \log \frac{\alpha^{\alpha \cdot \tau_{\ell}+(1-\alpha) \tau_{h}}}{u}(1-u)^{\alpha}\left(N_{h}\right)^{1-\alpha} \\
& +\quad \gamma \cdot N_{h} \log (1-\alpha)\left(1-\tau_{h}\right){\frac{1-u}{N_{h}}}^{\mathbf{q}_{\alpha}}
\end{aligned}
$$

The derivatives of $\Omega(., .,$.$) are:$

$$
\begin{aligned}
\Omega_{u}^{\prime}= & \log b-\log w_{\ell}-\frac{\alpha \cdot \tau_{\ell}+(1-\alpha) \tau_{h}}{b \cdot u}(1-u)^{\alpha}\left(N_{h}\right)^{1-\alpha} \\
& +\alpha \frac{1-u}{N_{h_{b} / 4}}{ }^{1 / 2}(1-\alpha) \frac{1-\tau_{\ell}}{w_{\ell}}-(1-\alpha) \frac{\gamma\left(1-\tau_{h}\right)}{w_{h}}-\frac{\alpha \cdot \tau_{\ell}+(1-\alpha) \tau_{h}}{b} \\
\Omega_{\tau_{\ell}}^{\prime}= & \frac{1}{b}-{\frac{1}{w_{\ell}}}^{1 / 2} \alpha(1-u)^{\alpha}\left(N_{h}\right)^{1-\alpha} \\
\Omega_{\tau_{h}}^{\prime}= & \frac{1}{b}-{\frac{\gamma}{w_{h}}}^{1 / 2}(1-\alpha)(1-u)^{\alpha}\left(N_{h}\right)^{1-\alpha}
\end{aligned}
$$

\section{A.1 The political equilibrium when negative income tax is allowed}

Here, we prove that $u=0$ at the political equilibrium when negative income tax is allowed. Assume by contradiction that $u>0$. One gets from first-order conditions $\Omega_{\tau_{\ell}}^{\prime}=\Omega_{\tau_{h}}^{\prime}=0$ that $b=w_{\ell}=w_{h} / \gamma$. Then, we can rewrite (27) as:

$$
\begin{aligned}
\Omega_{u}^{\prime} & =-\frac{\alpha \cdot \tau_{\ell}+(1-\alpha) \tau_{h}}{b \cdot u}(1-u)^{\alpha}\left(N_{h}\right)^{1-\alpha}-{\frac{\alpha}{w_{\ell}}}^{\mu} \frac{1-u}{N_{h}}{ }^{\mathfrak{q}_{\alpha-1}} \tau_{\ell} \\
& =-1-\frac{\tau_{\ell}}{1-\tau_{\ell}}=-\left(1-\tau_{\ell}\right)
\end{aligned}
$$

where the second equality is obtained thanks to $(5)$ and (26). Hence, $\Omega_{u}^{\prime}<0$. So positive unemployment cannot be optimal.

\section{A.2 The political equilibrium when negative income tax is forbidden}

First, we prove that when negative income tax is forbidden, we get $\tau_{\ell}=0$ and perfect unemployment insurance in case of unemployment. Assume by contradiction that the constraint $\tau_{\ell} \geq 0$ does not bind. Then, the first-order conditions would be $\Omega_{\tau_{\ell}}^{\prime}=\Omega_{\tau_{h}}^{\prime}=0$ and would lead to full employment and eventually one tax rate is negative. Hence, only a corner solution is feasible, implying $\Omega_{\tau_{l}}^{\prime} \leq 0$. 
From (28), this implies $b \geq w_{\ell}$. The only way to respect the participation constraint (10) is therefore to get perfect insurance and $b=w_{\ell}$.

Second, it is convenient to rewrite the political objective as a function of $w_{\ell}$ only. Since $\tau_{\ell}=0$ and $b=w_{\ell}$, we get from (8) and (18):

$$
w_{h}={\frac{\alpha}{w_{\ell}}}^{\text {ף } \frac{\alpha}{1-\alpha}}-\frac{w_{\ell}}{N_{h}} \quad \Rightarrow \quad \frac{w_{h}}{w_{\ell}}=\frac{1}{\alpha}^{\mu}{\frac{\alpha}{w_{\ell}}}^{\text {П } \frac{1}{1-\alpha}}-\frac{1}{N_{h}}
$$

so the government maximizes:

$$
\bar{\Omega}\left(w_{\ell}\right)=\log \left[w_{\ell}\right]+\gamma \cdot N_{h} \log { }^{\text {" }}{\frac{\alpha}{w_{\ell}}}^{\text {ף } \frac{\alpha}{1-\alpha}}-{\frac{w}{N_{h}}}^{\text {\# }}
$$

One gets

$$
\bar{\Omega}^{\prime}\left(w_{\ell}\right)=\frac{1}{w_{h}}{\frac{w}{w_{\ell}}}_{w_{\ell}} \cdot_{N_{h}} \frac{\alpha}{1-\alpha}^{\mu}{\frac{\alpha}{w_{\ell}}}^{\text {ी } \frac{\alpha}{1-\alpha}} \frac{1}{w_{\ell}}+\frac{1}{N_{h}}
$$

which can be simplified with (30):

$$
\bar{\Omega}^{\prime}\left(w_{\ell}\right)=\frac{1}{N_{h} \cdot w_{h}} \frac{1-\alpha\left(1+\gamma \cdot N_{h}\right)}{\alpha(1-\alpha)} N_{h}{ }^{\mu}{\frac{\alpha}{w_{\ell}}}^{\text {१ी } \frac{1}{1-\alpha}}-\left(1+\gamma \cdot N_{h}\right)
$$

The term into bracket is decreasing in $w_{l}$, which insures that function $\bar{\Omega}($.$) is quasi-concave. At an$ interior solution, one gets together with (17) and (31):

$$
\begin{aligned}
& 1-\bar{u}\left(w_{\ell}\right)=N_{\tilde{\AA}}{ }_{\tilde{\mathbf{A}}}^{\mu}{\frac{\alpha}{w_{\ell}}}^{\text {१ी } \frac{1}{1-\alpha}}=\underset{\mu}{(1-\alpha)} \frac{\alpha\left(1+\gamma \cdot N_{h}\right)}{1-\alpha\left(1+\gamma \cdot N_{h}\right)} \\
& \frac{w_{h}}{w_{\ell}}=\gamma 1+\frac{1}{1-\alpha} N_{h}{\frac{\alpha}{w_{\ell}}}^{\frac{1}{1-\alpha}}=\frac{\gamma}{1-\alpha\left(1+\gamma \cdot N_{h}\right)} \\
& w_{\ell}=\alpha{\frac{1-\alpha\left(1+\gamma \cdot N_{h}\right)}{(1-\alpha) \alpha\left(1+\gamma \cdot N_{h}\right)}}^{\mathfrak{ी}_{1-\alpha}}\left(N_{h}\right)^{1-\alpha} \\
& w_{h}={\frac{\alpha}{1-\alpha\left(1+\gamma \cdot N_{h}\right)}}^{\frac{\alpha}{(1-\alpha) \alpha\left(1+\gamma \cdot N_{h}\right)}}{ }^{\mathfrak{ी}_{1-\alpha}} \gamma\left(N_{h}\right)^{1-\alpha}
\end{aligned}
$$

Comparing this last equation with (15), high skilled workers prefers negative income tax to be forbidden (that is case 2a occurs instead of $2 b$ ) if and only if:

$$
\frac{\alpha}{1-\alpha\left(1+\gamma \cdot N_{h}\right)}{\frac{\boldsymbol{\mu}}{\alpha\left(1+\gamma \cdot N_{h}\right)}}^{\text {१ी }_{1-\alpha}}(1-\alpha)^{\alpha-1}>\frac{1}{1+\gamma \cdot N_{h}}
$$

This condition can be simplified into:

$$
\frac{\alpha\left(1+\gamma \cdot N_{h}\right)}{1-\alpha\left(1+\gamma \cdot N_{h}\right)}>(1-\alpha)^{\frac{1-\alpha}{\alpha}} \quad \Rightarrow \quad 1+\gamma \cdot N_{h}>\frac{1}{\alpha 1+(1-\alpha)^{\frac{\alpha-1}{\alpha}}}
$$


which gives equation (25). Redistribution occurs only if the right-hand side of (32) is smaller than 1. This implies

$$
(2-\alpha) \alpha\left(1+\gamma \cdot N_{h}\right) \leq 1 \quad \Rightarrow \quad \stackrel{\mathrm{h}}{1-(1-\alpha)^{\mathbf{i}^{\mathrm{i}}}\left(1+\gamma \cdot N_{h}\right) \leq 1}
$$

which leads to (22). For case 2a to appear, one needs to verify that

$$
2-\alpha<1+(1-\alpha)^{\frac{\alpha-1}{\alpha}}
$$

which is straightforward given that $\alpha \in(0,1)$ implies $(1-\alpha)^{\frac{\alpha-1}{\alpha}}>1-\alpha$.

\section{R eferences}

[1] Buchanan, J. M. and Tullock, G., 1962, The Calculus of consent, Ann Arbor Paperback.

[2] Epstein, G. and Nitzan S., 1999, The endogenous determination of minimum wage, IZA Discussion Paper 73.

[3] Immervoll, H,. 2004, Average and Marginal effective tax rates facing workers in the EU. A microlevel analysis of levels, distributions and driving force. EUROMOD working paper $\mathrm{n}^{\circ}$ EM06/04.

[4] Nickell, S. and Van Ours, J., 2000, The Netherlands and the United Kingdom: a European unemployment miracle?, Economic Policy, 30, 137-175.

[5] Persson, T. and Tabellini, G., 2000, Political Economics: Explaining Economic Policy, MIT Press.

[6] Piketty, T., 1999, Can fiscal redistribution undo skill-biased technical change ? Evidence from the French experience, European Economic Review, 43, 839-851.

[7] Saint-Paul G., 1994, Do labor market rigidities fulfill redistributive objectives ?, I.M.F. Staffs Papers 41(4), 624-642. 
[8] Saint-Paul, G., 1996a, Exploring the political economy of labour market institutions, Economic Policy, 23, 265-315.

[9] Saint-Paul, G.,1996b, Labour market rigidities and the cohesion of the middle class, International Tax and Public Finance, 3, 385-395.

[10] Saint-Paul, G., 2001, The political economy of labour market institutions, Oxford University Press, Oxford.

[11] Sobel, R., 1999, Theory and evidence on the political economy of the minimum wage, Journal of Political Economy, 107(4), 761-785. 